\title{
Corrosão
}

\section{Efeito da chuva ácida em aços inoxidáveis coloridos}

\author{
Célia Regina de Oliveira Loureiro \\ Eng. Química Mestre - Bolsista DTI CNPq da Fundação Centro Tecnológico de Minas Gerais/CETEC \\ E-mail: celia.loureiro@cetec.br \\ Ciomara Rabelo de Carvalho \\ Eng. Química Mestre - Pesquisadora Associada da Fundação Centro Tecnológico de Minas Gerais/CETEC \\ E-mail: ciomara.rabelo@cetec.br \\ José Antônio Cardoso \\ Químico - Pesquisador Pleno da Fundação Centro Tecnológico de Minas Gerais/CETEC \\ E-mail: jose.antonio.cardoso@cetec.br \\ Rosa Maria Rabelo Junqueira \\ Eng. Química - Pesquisadora Doutora da Fundação Centro Tecnológico de Minas/CETEC \\ E-mail: rosa.junqueira@cetec.br
}

\section{Resumo}

Em função da crescente demanda de utilização do aço inoxidável, na arquitetura, como material de revestimento externo e, considerando a preocupação dos órgãos de controle ambiental com a poluição no meio urbano, foram avaliados os efeitos da chuva ácida nas condições superficiais do aço inoxidável colorido e na lixiviação de cromo para o ambiente. Para esse estudo, foram realizados, em laboratório, ensaios de imersão de chapas de aço inoxidável colorido e natural em solução simulada de chuva ácida, sendo avaliados a liberação de cromo para a solução e a alteração da aparência superficial das amostras em tempos de exposição de 1, 3, 7, 14 e 28 dias. Nas amostras de aço inoxidável, com e sem coloração, foram medidos a cor e o brilho e, para soluções ácidas remanescentes, foram realizadas análises de cromo total e cromo hexavalente. Os resultados obtidos mostraram que, independente do tempo de contato do aço inoxidável colorido com a solução de chuva ácida, houve preservação da aparência do material, sem alteração das condições superficiais, e o teor de cromo hexavalente na solução se apresentou em níveis muito inferiores aos estabelecidos pelo Conselho de Política Ambiental de Minas Gerais - COPAM.

Palavras-chave: Aço inoxidável colorido, aparência superficial, chuva ácida, cromo hexavalente.

\begin{abstract}
Considering the increase of stainless steel application for exteriors in architecture and governmental environment protection policies, the effect of acid rain exposure on the surface appearance and chromium release of colored stainless steel and uncolored substrate was investigated. Laboratory experiments were conducted by immersing stainless steel samples in an artificial acid rain solution for 1, 3, 7, 14 and 28 days exposure. The surface appearance of the samples was evaluated by color and brightness measurements and chromium release by chemical analysis of total and hexavalent chromium. The obtained results have shown that the surface appearance of the stainless steel was preserved and the chromium release was lower than the levels permitted by the Brazilian local environment protection agency for water quality in Minas Gerais State.
\end{abstract}

Keywords: Colored stainless steel, surface appearance, acid rain, hexavalent chromium. 


\section{Introdução}

Os aços inoxidáveis, devido à sua durabilidade e diversidade de acabamentos superficiais, têm sido amplamente empregados na arquitetura, em revestimentos externos, e, também, na decoração de interiores. Os aços inoxidáveis podem ser coloridos por eletrodeposição de um filme de óxidos de cromo, na superfície dos aços inoxidáveis, que, ao interagir com a luz ambiente, provoca o aparecimento de cores de interferência, que se sucedem do bronze, azul, dourado, vermelho, verde e preto, à medida que aumenta a espessura do filme. A coloração pode ser realizada em qualquer tipo de acabamento mecânico, seja ele escovado ou brilhante, o que amplia, consideravelmente, as possibilidades de aplicação do aço inoxidável nos projetos arquitetônicos, acrescentando mais calor e vida aos mesmos [Junqueira et al., 2004].

A necessidade de se avaliar o desempenho dos aços inoxidáveis com ou sem coloração tem motivado a realização de diversos trabalhos de pesquisa que abrangem estudos de resistência mecânica [Junqueira et al., 2006, Junqueira et al., 2001] e resistência à corrosão [Santadréa et al., 2001, Conrrado et al., 2003, Junqueira et al., 2004,] até a liberação de constituintes metálicos, tais como $\mathrm{Cr}$ e $\mathrm{Ni}$, que possam produzir efeitos nocivos à saúde humana e ao meio ambiente [Wallinder et al., 2002; Persson et al., 2000].

Com o passar dos anos, a preocupação com a política ambiental no mundo e, especialmente, na Europa vem se intensificando. Entre as diversas preocupações com fatores de risco, têm-se os questionamentos sobre uso futuro de aços contendo cromo, níquel, cobre e zinco, em construções urbanas. A atenção se volta para a possibilidade de liberação desses metais pela ação das intempéries com a presença da chuva ácida, ocorrência freqüente nos grandes pólos industriais [Wallinder et al., 2002]. Dentro deste contexto, estudos sobre a estabilidade química de aços têm sido realizados pelas determinações dos graus de liberação de metais, a partir de ensai- os de campo e de simulações em laboratório. As taxas de dissolução de constituintes dos aços inoxidáveis já foram avaliadas em diversos meios como saliva artificial, soluções de ácido acético, cloreto de sódio, ácido sulfúrico e de chuva ácida simulada, entre outras [Walterson, 1999].

Do exposto anteriormente e considerando a necessidade de caracterização do aço inoxidável colorido, como apoio ao direcionamento das aplicações do produto, esse trabalho teve, por objetivo, avaliar os efeitos da chuva ácida na aparência do aço colorido, bem como na lixiviação de cromo hexavalente para o meio ambiente. Os resultados obtidos com essa pesquisa poderão ser utilizados, também, para responder às questões ambientais já apresentadas pelo mercado europeu, de modo a alavancar as exportações desse produto.

\section{Metodologia}

Amostras de aço inoxidável ABNT 304 com acabamento mecânico escovado ("Rugged Finish") e composição química nominal, conforme Tabela 1, e amostras de aço inoxidável ABNT 304 coloridas em dourado, pelo processo eletroquímico de corrente pulsada [Cetec, 1999], foram preparadas para ensaios de imersão em solução de chuva ácida simulada. Para cada tipo de material foram utilizadas 30 amostras, com dimensões de $2,0 \mathrm{~cm}$ x $8,0 \mathrm{~cm}$.

Os ensaios consistiram na imersão de amostras previamente lavadas com detergente neutro e água, na solução de chuva ácida simulada, por períodos preestabelecidos. Após um determinado tempo de imersão, as amostras foram novamente lavadas e avaliadas quanto ao grau de modificação da aparência super- ficial, a partir de parâmetros de cor e brilho. Nas soluções remanescentes, foram determinados os teores de cromo total dissolvido e cromo hexavalente.

Para preparação da solução de chuva ácida, foi tomado, como referência, o procedimento padrão GM9625P. Essa solução consiste em uma mistura balanceada de ácido sulfúrico, ácido nítrico e ácido clorídrico, permitindo ajuste da acidez final, a partir do nível de diluição de uma solução-mãe. Entre as condições permitidas por esse procedimento, para o pH final da solução, foi selecionada a mais crítica, com pH 4,0.

Para os ensaios de imersão, foram preparados 30 frascos de vidro com capacidade de $20 \mathrm{ml}$. Em 15 frascos, foram completamente imersas amostras de aço colorido em dourado, sendo duas amostras por frasco. Nos demais, foram imersas as amostras de aço não colorido (substrato), também com duas amostras por frasco. Foram programadas retiradas em triplicatas com 1, 3, 7, 14 e 28 dias.

Para determinação numérica da cor, foi utilizada técnica de espectrofotometria de refletância na faixa de comprimento de onda da luz visível. A escala empregada foi a LCh, com ângulo de observação de $10^{\circ}$, e iluminante $\mathrm{D}_{65}$, o qual corresponde à luz do dia. As variações de cor, antes e após imersão, foram avaliadas pela diferença de cor $\left(\Delta \mathrm{E}_{\mathrm{cmc}}\right)$, obtida a partir das três coordenadas cromáticas: L: Luminosidade, C: saturação e h: tonalidade.

As medidas numéricas do brilho, na superfície das amostras ensaiadas, foram realizadas em um medidor de brilho (micro-TRI-gloss da BYK Gardner), utilizando ângulo de observação de $20^{\circ}$ e janela de medida de $1,0 \mathrm{~cm}$ x 1,0 cm. A determinação foi realizada na direção da laminação. O resultado obtido foi expresso em unidades de brilho (UB).

Tabela 1 - Composição química nominal (\% em peso) do aço inoxidável ABNT304.

Composição Química (\% em peso)

\begin{tabular}{c|c|c|c|c|c|c|c}
\hline $\mathbf{C}$ & $\mathbf{M n}$ & $\mathbf{S i}$ & $\mathbf{P}$ & $\mathbf{S}$ & $\mathbf{C r}$ & $\mathbf{N i}$ & Outros \\
\hline$<0,08$ & $<2,00$ & $<1,00$ & $<0,045$ & $<0,030$ & 18 a 20 & 8 a 10,50 & -- \\
\hline
\end{tabular}


Célia Regina de Oliveira Loureiro et al.

As determinações dos teores de cromo total, nas soluções de chuva ácida, em diferentes tempos de imersão, foram realizadas conforme a norma APHA 3120 B (American Public Health Association, 2005), a qual utiliza o método de espectrometria de plasma indutivamente acoplado. A dosagem do cromo hexavalente foi realizada conforme a norma APHA 3500-Cr (American Public Health Association, 2005) baseada no método colorimétrico.

\section{Resultados e discussão}

As diferenças de cor $\left(\Delta \mathrm{E}_{\mathrm{cmc}}\right)$ e brilho que ocorreram decorrente do contato do aço inoxidável colorido e do substrato com a solução de chuva ácida simulada estão apresentadas nas Figuras $1 \mathrm{e} 2$.

Pelos resultados apresentados, observa-se que, em relação ao parâmetro diferença de cor $\left(\Delta \mathrm{E}_{\mathrm{cmc}}\right)$, o substrato apresentou menor alteração, quando comparado ao aço colorido. O comportamento inverso foi observado com relação à diferença de brilho.

Para o substrato, o maior impacto na aparência da superfície do aço, após o contato com solução ácida, é a perda da alta reflexão especular, característica inerente dos aços inoxidáveis. No caso do aço colorido, a componente de cromaticidade, parâmetro relacionado à quantificação e pureza da cor, é mais influenciada pelo tempo de imersão, de maneira a ocasionar maior diferença no $\Delta \mathrm{E}_{\mathrm{cmc}}$. Entretanto os valores numéricos encontrados para as diferenças de aparência, tanto para brilho, como para cor, não são percebidos pelo olho humano. Assim, na inspeção visual do aço colorido após o tempo de imersão de 28 dias, em chuva ácida de $\mathrm{pH}=4$, não foi observada alteração em sua coloração. Podese dizer, ainda, que não houve variação da aparência superficial das amostras com o tempo de imersão.

Na avaliação da dissolução de cromo em solução, a Tabela 2 apresenta os

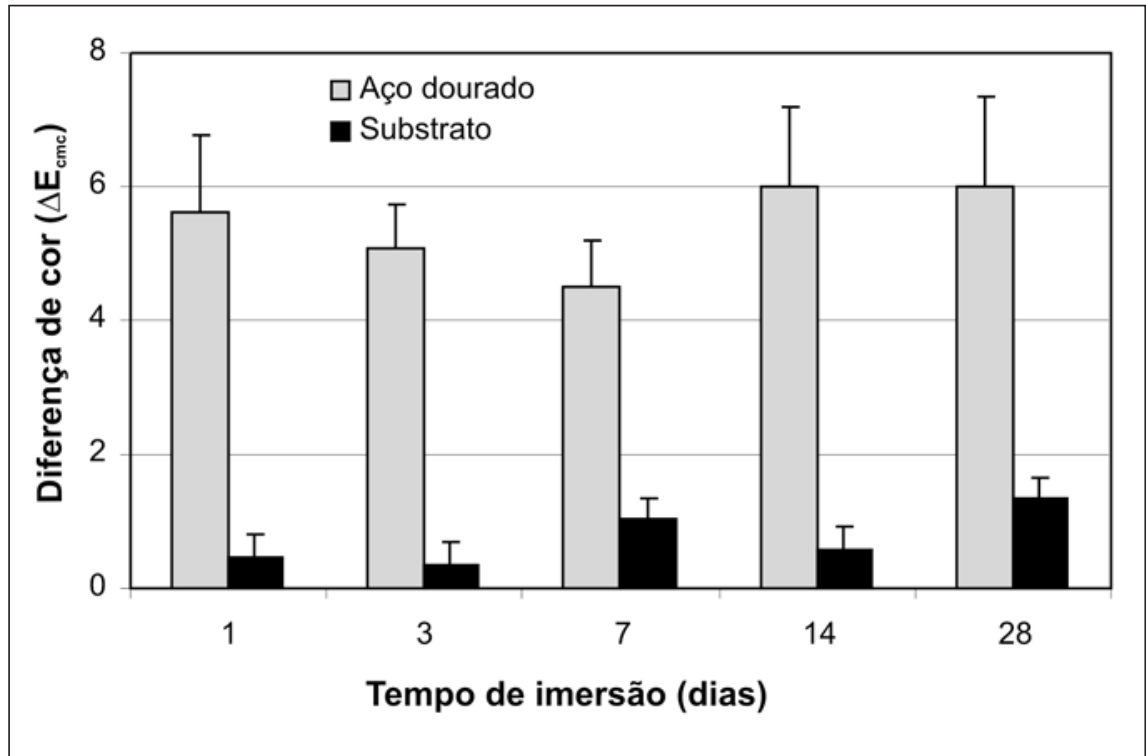

Figura 1 - Valores médios das diferenças de cor obtidas pelas medidas das coordenadas cromáticas (LCh) realizadas nas superfícies das amostras antes e após imersão em chuva ácida simulada pelo tempo indicado.

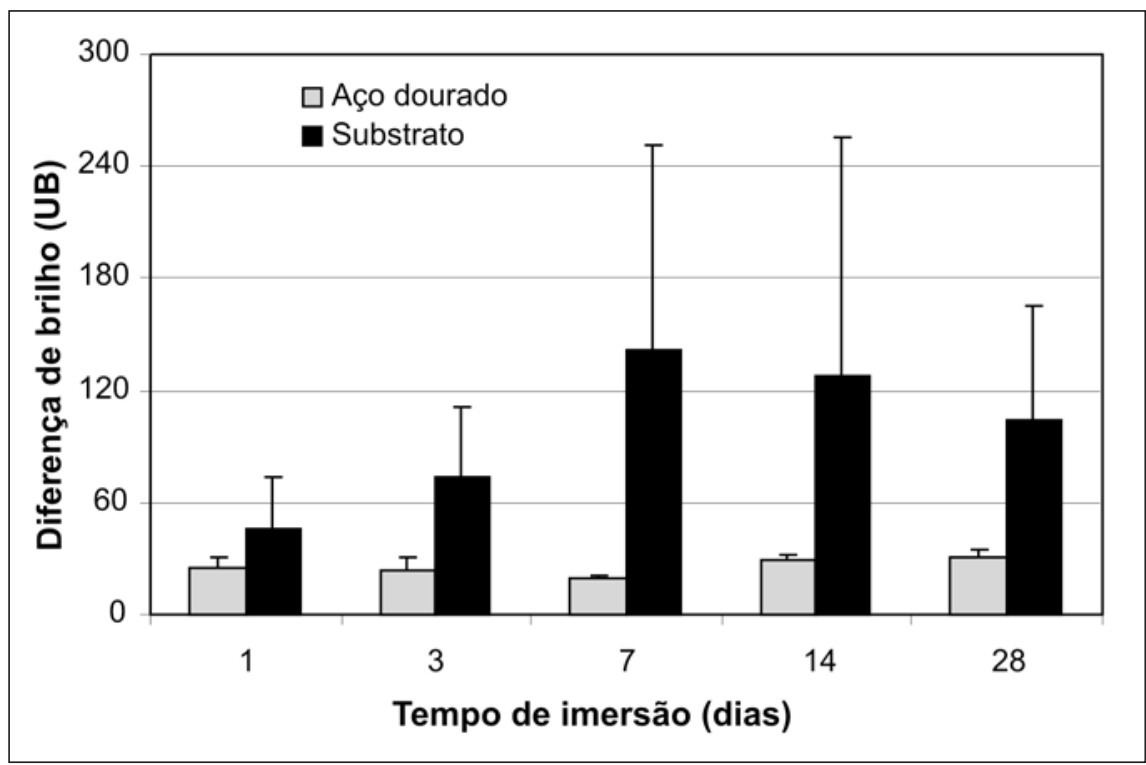

Figura 2 - Valores médios das diferenças de brilho obtidas pelas medidas realizadas nas superfícies das amostras antes e após imersão em chuva ácida simulada pelo tempo indicado.

resultados obtidos nas determinações dos teores de cromo total, dissolvido e cromo hexavalente, realizadas nas soluções ácidas remanescentes das imersões dos aços inoxidáveis coloridos e naturais.

Pelos resultados apresentados na Tabela 2, constata-se que as concentrações do cromo total dissolvido e do cromo hexavalente estão muito abaixo dos limites máximos permitidos pela norma ABNT NBR 1004 (Cr total $<5$ mg/L), que classifica os resíduos quanto aos seus riscos potenciais ao meio ambiente e à saúde pública, e pela Deliberação Normativa $\mathrm{N}^{\circ} 10$, de 1986 , e $\mathrm{DN} 10 / 86$, que estabelece normas e padrões para qualidade das águas, lançamento de efluentes nas coleções de águas e dá outras providências (Cr VI<0,05 mg/L). 
Não foram também observadas diferenças nas concentrações de cromo com o tempo de imersão. As soluções ácidas, onde foram imersas amostras de aço inoxidável colorido, não se apresentaram com diferentes concentrações, quando comparadas com aquelas utilizadas nas amostras sem coloração. Isto sugere que, pela metodologia empregada, o aço inoxidável colorido não libera mais cromo na solução do que o não colorido, apesar de o mesmo apresentar um filme de óxido de cromo consideravelmente mais espesso na sua superfície que o filme passivo dos aços inoxidáveis naturais sem coloração.

\section{Conclusões}

A imersão de amostras de aços inoxidáveis coloridos e naturais sem coloração, em solução de chuva ácida simulada, mostrou que:

- A aparência da superfície das amostras, medida por parâmetros de cor e brilho, não apresentou alterações perceptíveis ao olho humano, por períodos de imersão de até 28 dias.

- Nas condições ensaiadas, não houve diferença na quantidade de cromo liberada para a solução de chuva ácida ao se compararem as amostras de aço inoxidável natural e colorido.

- Os teores residuais de cromo total determinados estão abaixo dos limites máximos permitidos pela NBR 1004, independente do tempo de imersão.

- Os teores de cromo hexavalente determinados, independente do tempo de imersão, encontram-se abaixo do limite estabelecido para classificação de águas classe 1 da legislação do Estado de Minas Gerais.

- Não existe risco de uso do aço inoxidável colorido e natural em aplicações externas que possam estar em contato com chuva ácida.

\section{Agradecimentos}

Os autores agradecem à Fapemig pelo apoio financeiro às pesquisas reali-

Tabela 2 - Valores médios dos níveis de cromo total dissolvido e hexavalente determinados a partir da solução de chuva ácida simulada após testes de imersão.

\begin{tabular}{c|c|c|c|c}
\hline \multirow{2}{*}{$\begin{array}{c}\text { Tempo de } \\
\text { imersão } \\
\text { (dias) }\end{array}$} & \begin{tabular}{c} 
Cromo hexavalente mg/L * \\
\cline { 2 - 5 } \\
coloração
\end{tabular} & $\begin{array}{c}\text { ABNT 304 } \\
\text { colorido }\end{array}$ & $\begin{array}{c}\text { ABNT 304 sem } \\
\text { coloração }\end{array}$ & $\begin{array}{c}\text { ABNT 304 } \\
\text { colorido }\end{array}$ \\
\hline 1 & $<0,01$ & $<0,01$ & $<0,04$ & $<0,04$ \\
\hline 3 & $<0,01$ & $<0,01$ & $<0,04$ & $<0,04$ \\
\hline 7 & $<0,01$ & $<0,01$ & $<0,04$ & $<0,04$ \\
\hline 14 & $<0,01$ & $<0,01$ & $<0,04$ & $<0,04$ \\
\hline 28 & $<0,01$ & $<0,01$ & $<0,04$ & $<0,04$ \\
\hline
\end{tabular}

${ }^{*}$ Média de 3 determinações.

zadas para desenvolvimento e caracterização do aço inoxidável colorido e pela Bolsa de Desenvolvimento Tecnológico Industrial concedida a Célia Regina de Oliveira Loureiro, durante a realização dessas pesquisas.

\section{Referências bibliográficas}

CETEC - FUNDAÇÃO CENTRO TECNOLÓGICO DE MINAS GERAIS, Belo Horizonte-MG, Rosa Maria Rabelo Junqueira e Rogério Gonçalves Marques. Processo de coloração de aços inoxidáveis coloridos. Patente PI19703991, carta patente expedida em 03.01.2006. Revista da Propriedade Industrial, Rio de Janeiro, n.1464, 1999.

CONRRADO, R., BOCCHI, N., BIAGGIO, S., ROCHA-FILHO, R.C. Corrosion Resistance of Colored Films Grown on Stainless Steel By The Alternating Potencial Pulse Method. Eletrochimica Acta, v.48, n.17, p.2417-2424, 2003.

GM9625P Procedimento Padrão de Engenharia. Preparação de solução de chuva ácida. General Motors Corporation, 1997.

JUNQUEIRA, R. M. R., ANDRADE, M.S., LOUREIRO, C.R.O., BUONO, V. T. L. Mechanical properties of interference thin films on colored stainless steel evaluated by depth-sensing nanoidentation. Surface and Coatings Technology, Amsterdam, 2006.

JUNQUEIRA, R.M., LOUREIRO, C.R. Avaliação da resistência à corrosão de aços inoxidáveis ABNT 304 coloridos por interferência. In: SEMINÁRIO
BRASILEIRO DO AÇO INOXIDÁVEL - INOX 2004, 7. Anais... São Paulo, 2004.

JUNQUEIRA, R.M., ANDRADE, M.S., GOMES, O.A., OLIVEIRA, N.J.L., SOUZA, W.A., BUONO,V.T.L. Comportamento do filme de interferência durante a deformação de aços inoxidáveis coloridos. In: CONGRESSO ANUAL DA ASSOCIAÇÃO BRASILEIRA DE METALURGIA E MATERIAIS - ABM, 56. Anais..., Belo Horizonte, 2001. p.442-451.

PERSSON, D., KUCERA, V. Release of metals from buildings, constructions and products during atmospheric exposure in Stockholm. Watter, Air and Soil Polution: Focus 1: 133-150, 2001.

SANTANDRÉA, R., MIRANDA, L.R.M. Aspectos da corrosão atmosférica de aços inoxidáveis ferríticos estabilizados. In: CONBRASCORR - CONGRESSO BRASILEIRO DO AÇO INOXIDÁVEL - INOX 99, 21. Anais..., São Paulo, p.152-160, 1999.

WALLINDER, O.I., LU J., BERTLING, S., LEYGRAF C. Release Rates of Chromium and Nickel from 304 and 316 stainless steel during urban atmospheric exposure - a combined field and laboratory study. Corrosion Science, v.44, p.2303-2319, 2002.

WALTERSON, E. apud WALLINDER, O.I., LU J., BERTLING, S., LEYGRAF C. Release Rates of Chromium and Nickel from 304 and 316 stainless steel during urban atmospheric exposure - a combined field and laboratory study. Corrosion Science, v.44, p.2303-2319, 2002.

Artigo recebido em 30/07/2006 e aprovado em 05/10/2006. 